remained practically unchanged. In group 3, moreover, the percentage of myofibril nitrogen-which in the controls was more than twice as high as that of sarcoplasm nitrogen-had declined by about onethird, and the percentage of sarcoplasm nitrogen had increased to about the same level as myofibril nitrogen. Changes with the same tendency were observed in group 2.

Since atrophy invariably increases the proportion of stroma in a muscle, and since it remained unchanged here, this shift cannot have been caused by any kind of atrophy. Nor can pathological factors have been involved. But the muscles in group 2, where age changes cannot have occurred, exhibited changes of apparently the same fundamental type as, only of lesser degree than, the changes observed in group 3. However, the possibility that ageing might produce similar changes in animals that have maintained a constant activity-level throughout their lives cannot be ruled out entirely. Yet irrespective of how the variation arises, the composition of the muscle cell can evidently vary greatly from one normal individual to another.

Changes of this type-for which allomorphosis would seem to be an apt term ( $\alpha^{\prime} \lambda \lambda \circ \sigma$, other; $\mu \circ \rho \varphi \eta \dot{\eta}$, shape)-are due to adaptation of the cell in various circumstances, the degree of activity being a causative factor in the case of the muscle cell. Conceivably, other cells in the organism also undergo allomorphosis.

Hitherto the consensus of opinion appears to have been that the cells in a tissue are of fairly constant composition, and that the proportions of the various cell constituents will change greatly only under pathological conditions. But here it has been demonstrated that, at least in muscular tissue, the composition of individual cells may undergo considerable variations even under normal conditions.

Allomorphosis of the muscle cell must clearly be accompanied by changes in its contractile power. A muscle in which the cells contain a sharply reduced proportion of contractile proteins, and concomitantly an increased proportion of sarcoplasm proteins, cannot be as powerful as an unchanged muscle. Accordingly, because the composition of muscle fibres may vary so greatly, the contractile powers of two muscles cannot be compared solely on the basis of the effective areas of the muscle cross-sections.

Institute of Anatomy,

University of Gothenburg, Sweden.

July 21.

1 H.elander, E., Acta Physiol. Scand. Suppl., 41.141 (1957).

\section{Salt Requirements in the Tropics during Summer}

IN a recent communication, Dahl ${ }^{1}$ has stated that a considerable reduction in quantity of salt intake can be made from the existing levels, without any harm to the body. This may, on the other hand, be of great benefit in reducing the incidence of hypertensive cardiovascular disease. The treatment of hypertension by low salt diet is quite well established, but it was not known before that persons on habitually high salt diet are more prone to essential hypertension and its complications. Dahl has predicted that where salt diet exceeds $5 \mathrm{gm}$. of sodium per day (that is, $12.5 \mathrm{gm}$. sodium chloride) incidence of hypertension and its complications will be frequent.

This statement may be true of cold and temperate climates where there is practically no loss of salt in sweat and all the dietary salt is excreted in urine (negligible amounts also in fæces and saliva). In the tropics, on the other hand, excretion of salt in sweat is quite appreciable and is higher in those unacclimatized than in those acclimatized. This is because in acclimatized persons the concentration of salt in sweat is comparatively less, due to the influence of adrenal hormones. Therefore requirement of salt is different for the two. When, after living in a hot climate, a person gets acclimatized to heat, his requirement of salt is also reduced.

Our studies have shown ${ }^{2}$ that in an environmental temperature of about $101^{\circ} \mathrm{F}$. and relative humidity 54 per cent, acclimatized subjects sweating 3-5 l./day could be kept in salt balance on $6 \cdot 2 \mathrm{gm}$./day. The requirement of salt has been found to increase proportionally with rise in dry-bulb temperature of the environment. When the maximum day temperature is about $110^{\circ} \mathrm{F}$., the requirement of salt has been found to be about $15 \mathrm{gm}$. for an acclimatized person working for $8 \mathrm{hr}$. a day. These results have been supported by observations on ratings working in Indian Navy ships for $8 \mathrm{hr}$. a day in the engine room, where the dry-bulb temperature of the environments was of the order of $110^{\circ} \mathrm{F} .^{3}$, and no case of salt deficiency was recorded on salt intake of $15 \mathrm{gm}$. a day. Observations in the textile industry in India ${ }^{4}$ have also shown that there is no salt depletion in workers working at temperatures up to $86^{\circ} \mathrm{F}$. effective temperature for $8 \mathrm{hr}$. on a normal salt intake of about $15 \mathrm{gm} . /$ day.

It has been also found ${ }^{2}$ that the physiological requirement of salt is less than that needed for balancing taste in food. If enough salt is taken to satisfy the palate, there is very little likelihood of salt deficiency occurring in the body.

Low incidence of hypertension in India is not due to low salt intake as suggested by $\mathrm{Dahl}^{1}$; but is probably due to heavy losses of salt in sweat. The salt content of the Indian dietary varies from 14 to $24 \mathrm{gm}$. a day from north to south ${ }^{5}$, which is more than that of Western countries, where the diet contains 10-15 gm. salt a day ${ }^{6}$.

From the foregoing it can be concluded that about $15 \mathrm{gm}$. of salt ( $6 \mathrm{gm}$. sodium) is quite adequate for acclimatized persons engaged in manual work in the tropics, and that for sedentary persons about $6 \mathrm{gm}$. salt a day is quite enough.

My thanks are due to Prof. D. S. Kothari, scientific adviser to the Minister of Defence, for his interest in this work and permission to publish this communication.

\section{Mangal Sain Malhotra}

Defence Science Laboratory, Ministry of Defence, New Delhi, 12. July 24.

${ }^{1}$ Dahl, L. K., Nature, 181, 989 (1958).

${ }^{2}$ Malhotra, M. S., Sivaraman, R., and Balkrishan, Ministry of Defence, Defence Science Organization (India) Report No. $3 / 56$ (1956).

${ }^{3}$ Malhotra, M. S., and Bhattacharya, M. N., Ministry of Defence Defence Science Organization (India) Report No. 10/54 (1954).

* The Chief Adviser Factories, Ministry of Labour and Employment, Government of India, New Delhi, Report No. 17 (1957)

- National Sample Survey Depot of Economic Affairs, Ministry of Finance, Government of India Report No. 1, Table $Q$ (1952).

"Leitch, J. N., "Dietetics in Warm Climate" (Harrison and Sons, Ltd., London; 1930). 